\title{
Anesthesia for ambulatory surgery
}

\author{
Korean Journal of Anesthesiology Jeong Han Lee \\ Department of Anesthesiology and Pain Medicine, Busan Paik Hospital, Inje University College of Medicine, Busan, \\ Korea
}

Ambulatory anesthesia allows quick recovery from anesthesia, leading to an early discharge and rapid resumption of daily activities, which can be of great benefit to patients, healthcare providers, third-party payers, and hospitals. Recently, with the development of minimally invasive surgical techniques and short-acting anesthetics, the use of ambulatory surgery has grown rapidly. Additionally, as the indications for ambulatory surgery have widened, the surgical methods have become more complex and the number of comorbidities has increased. For successful and safe ambulatory anesthesia, the anesthesiologist must consider various factors relating to the patient. Among them, appropriate selection of patients and surgical and anesthetic methods, as well as postoperative management, should be considered simultaneously. Patient selection is a particularly important factor. Appropriate surgical and anesthetic techniques should be used to minimize postoperative complications, especially postoperative pain, nausea, and vomiting. Patients and their caregivers should be fully informed of specific care guidelines and appropriate responses to emergency situations on discharge from the hospital. During this process, close communication between patients and medical staff, as well as postoperative followup appointments, should be ensured. In summary, safe and convenient methods to ensure the patient's return to function and recovery are necessary.

Key Words: Ambulatory surgical procedures, Anesthesia, Patient safety, Patient selection.

\section{Introduction}

The rate of ambulatory surgery use has increased steadily due to continued improvements in anesthesia techniques, such as regional anesthesia, and the availability of ultrashort-acting anesthetics with reduced side effects. More appropriate ambulatory discharge criteria and minimally invasive surgical techniques have also increased the rate of ambulatory surgery use [1-3]. Consistent with these changes, the introduction of the concept

Corresponding author: Jeong Han Lee, M.D., Ph.D.

Department of Anesthesiology and Pain Medicine, Busan Paik Hospital, Inje University College of Medicine, 75, Bokji-ro, Busanjin-gu, Busan 47392, Korea

Tel: 82-51-890-6520, Fax: 82-51-898-4216

Email: ljh646@inje.ac.kr

ORCID: https://orcid.org/0000-0002-4616-0355

Received: March 15, 2017.

Accepted: April 5, 2017.

Korean J Anesthesiol 2017 August 70(4): 398-406 https://doi.org/10.4097/kjae.2017.70.4.398 of fast-track recovery in the early 1990s enabled quicker recovery from anesthesia and thus a rapid resumption of daily activities and early discharge from the hospital [4,5]. Mortality and major morbidity associated directly with ambulatory surgery have a very low incidence [1] and there are several important advantages of ambulatory surgery when compared to inpatient surgeries, such as a lower rate of cancellations, and reductions in waiting times, hospital costs, and the risk of nosocomial infection [6]. At first, ambulatory surgery went largely unnoticed, but in the 1960s it started to gain prominence along with ambulatory anesthesia at general hospitals. In 1985, the Society of Ambulatory Anesthesia (SAMBA) was founded, and in 1995, the International Association of Ambulatory Surgery (IAAS) was established by surgeons, anesthesiologists, nurses, and hospital managers [7]. Since then, the use of ambulatory anesthesia has increased rapidly; now, 65-70\% of all operations in the United States are performed on an ambulatory basis [8].

For a successful ambulatory surgery, it is necessary that both the patient and the procedure are appropriate for ambulatory anesthesia. The advantages of ambulatory surgery disappear in cases in which an emergency occurs or an unplanned hospital

(c) This is an open-access article distributed under the terms of the Creative Commons Attribution Non-Commercial License (http://creativecommons.org/ licenses/by-nc/4.0/), which permits unrestricted non-commercial use, distribution, and reproduction in any medium, provided the original work is properly cited. 
admission is required. Thus, patients intending to undergo an ambulatory operation should consider the numerous potential risks involved. The primary concern in ambulatory surgery is ultimately the patient's health and the potential side effects. Thus, when deciding on ambulatory surgery, it is important to evaluate the patient's overall condition, including their past medical history and family history, as well as the type of surgery. The choice of anesthetic method is based on the operation, patient factors, the anticipated degree of pain, and possible complications. However, considering that ambulatory surgeries involve discharge on the day of the operation, recovery of the patient is perhaps the most important factor in determining the method of anesthesia. For successful ambulatory surgery, prophylactic and active treatment should be performed to minimize complications, such as postoperative pain, nausea, and vomiting, which may delay discharge and increase the likelihood of unanticipated hospital readmission during the perioperative period. This article will discuss patient selection, anesthetic methods, and postoperative management for effective ambulatory anesthesia.

\section{Preoperative Anesthetic Assessment}

Preoperative assessment of patients for ambulatory surgery confers several advantages. First, surgery cancellations and delays can be reduced [6,9-11]. Cancellation of surgery not only increases time and monetary costs, but also increases the pain of the patient. Second, a preoperative evaluation should improve the patient's condition and allows adjustment to improve suitability for ambulatory surgery. That is, the patient's condition can be improved, in terms of suitability for ambulatory surgery, by uncovering their health problems [12]. Third, effective evaluations speed up the whole process, thus saving time [13].

\section{Patient selection}

Most patients are eligible for ambulatory surgery unless there is a specific reason for an overnight stay [14]. Recently, patient choice has become an important factor because of the complexity of ambulatory surgical procedures and the increased incidence of comorbidities. Preoperative assessment and optimization according to medical comorbidities are associated with improved perioperative results.

Patient selection for ambulatory surgery depends on several factors, including surgical, social, medical, and anesthetic factors.

\section{Surgical considerations [14]}

1. Ambulatory surgery should not carry a significant risk of major complications (e.g., hemorrhage, cardiovascular instability).

Online access in http://ekja.org
2. When opening the abdominal or thoracic cavities, minimally invasive surgical techniques should be used.

3. Postoperative pain should be controlled with oral analgesia and regional or local anesthetic techniques.

4. Patients should be able to resume normal functions (e.g., oral drinking) as soon as possible.

5. Patients should be mobile to at least some extent before discharge.

6. Long-term professional care or observation after surgery is not required.

7. The anticipated degree of surgical trauma is more important than the surgical duration.

8. The surgeon should have sufficient experience with the procedure and a low complication rate record.

\section{Social considerations [14]}

1. Patients must understand the procedure and postoperative care requirements and consent to the ambulatory surgery.

2. When a patient is discharged to home, he/she should be accompanied by a responsible adult who can take care of them in the $24 \mathrm{~h}$ after surgery.

3. It is essential for patients and caregivers to have easy access to a telephone after discharge.

4. Patients should not drive for at least $24 \mathrm{~h}$ after anesthesia or sedation.

5. It is also important to be within $1 \mathrm{~h}$ of emergency medical services and to minimize pain.

6. The patient's home environment should be suitable for postoperative care.

\section{Medical considerations}

1. Patient selection is based on the patient's functional status at the time of assessment and is not necessarily restricted by age, body mass index (BMI), or American Society of Anesthesiologists status [15-17]. While a high BMI is not an absolute contraindication [18], obese patients may have other medical problems, such as obstructive sleep apnea (OSA) [19]. In the case of obese patients, the preoperative assessment must be sufficiently thorough to identify patients with obesity-related diseases and to exclude those with severe coexisting diseases that may be better managed in a hospital setting.

2. Patients with chronic but stable illnesses prefer to be at home, as this interferes less with their daily lives [15].

3. Patients with unstable medical condition, such as unstable angina or poorly controlled diabetes, are not appropriate for ambulatory surgery. 


\section{Anesthetic considerations}

In addition to a general medical assessment, there are also specific areas that should be addressed, including anesthesia history and postoperative nausea and vomiting (PONV) risk an airway assessment should also be done.

\section{Anesthetic history}

It is important to investigate anesthesia-related problems, such as suxamethonium (succinylcholine) apnea [20], malignant hyperthermia and other related complications, and to check for a family history of bad reactions and obtain relevant documents. Such complications are not necessarily absolute contraindications, but additional preparation may be necessary if they are present. There is a possibility of malignant hypersensitivity $(<$ $1 \%)$ even after the administration of a trigger-free anesthetic $[21,22]$, postoperative temperature monitoring for at least $4 \mathrm{~h}$ is recommended [23].

\section{PONV risk}

PONV is the most common complication of anesthesia and the risk varies greatly according to the anesthesia method. In preoperative evaluations, it is useful to evaluate the risk of PONV using the four Apfel risk factors (female gender, history of PONV and/or motion sickness, non-smoking status, and postoperative use of opioids) [24]. This makes it possible to classify patients into risk groups for better planning of anesthesia.

\section{Airway assessment}

To predict difficult airway intubation, a preoperative airway examination should be done. Certain patient groups, such as those with OSA and obesity, may be at higher risk for anesthesia-related complications but appropriate patient and treatment selection can prevent airway-related complications. Supraglottic devices must be evaluated carefully to determine the role of routine and emergency airway management in the ambulatory setting [25].

\section{Special considerations}

\section{Elderly populations}

As the general population ages and lifespans increase, the number and severity of medical complications that require cardiovascular drugs is also increasing [26]. However, age alone should not be used to determine the appropriateness of ambulatory surgery. Preoperative assessment should be done to determine whether there are any exclusion criterion for ambulatory surgery. Older outpatients need more supervision after discharge and social issues, such as patient independence, mobility, and familial or social isolation, should be considered for this population. Postoperative cognitive dysfunction may be better managed at home, in a familiar environment, to allow more rapid discharge after ambulatory surgery [17].

\section{Obstructive sleep apnea}

Among patients with OSA, it is known that the risk of perioperative complications is high [27]. However, evidence from a recent systematic review suggests that there is no increased risk of morbidity or mortality in patients with OSA who undergo ambulatory surgery [28]. Based on this evidence, a consensus statement by the SAMBA, patients with a known diagnosis of OSA who are typically undergoing continuous positive airway pressure (CPAP) therapy, were optimized, and during the postoperative period, a CPAP device can be used [29]. If OSA has not been diagnosed, signs and symptoms should be checked for during evaluations in groups at particular risk. The STOP-Bang questionnaire helps in predicting the likelihood of OSA [29]. This instrument is a quick tool for evaluating undiagnosed OSA patients and helps anesthetists prepare appropriate postoperative monitoring and care regimens $[29,30]$.

\section{Intraoperative Anesthetic Management}

No single anesthetic or method is appropriate for all ambulatory anesthesia cases. Thus, the patient's preference, age and physical condition, the surgeon's requirements, the duration of effect of the selected medication, and the degree of postoperative nursing care required are considered in determining the most effective and convenient anesthetic method and medication. The choice of anesthetic method for ambulatory surgery should also take into account the safety, quality, efficacy, medicine, and equipment of the different methods. Furthermore, in general, the anesthetic agents that are chosen are those with a rapid onset of action and fast recovery time, and that do not cause problems with respect to intraoperative control of consciousness and pain relief, and have no other side effects. The choice of anesthetic method depends on the type of surgery and the patient's status. Anesthesia for ambulatory surgery includes general and regional anesthesia, local anesthesia, monitored anesthesia care (MAC), or a combination of these methods.

\section{General anesthesia}

General anesthesia is the most common choice, because it is safe, economical, easy to recover from, and familiar to most anesthesiologists. The use of new anesthetics, such as propofol, sevoflurane, and desflurane, allows for easier titration, early awakening, and a reduction in the time required to meet postanesthesia care unit (PACU) discharge criteria [31-34]. However, the absence of analgesia during the postoperative period 
requires the addition of opioids, which carry risks of mental obtundation and nausea.

Inhalational agents themselves carry a $20-50 \%$ risk of PONV [35], which can be minimized by generous use of prophylactic drugs [36]. The value of using of desflurane versus sevoflurane remains open to discussion [37]. Although the clinical difference between desflurane and sevoflurane is small, in some studies, more rapid emergence from anesthesia was reported with desflurane [38]. Another study reported that in a desflurane group, emergence from anesthesia was more rapid compared with a sevoflurane group, but there were no significant differences between the two groups during the late recovery phase [39].

As an intravenous anesthetic, propofol shows a rapid rate of metabolism, resulting in quick recovery from anesthesia with few side effects [40]. Because of the low incidence of nausea and vomiting, propofol is commonly used for anesthesia induction and maintenance in ambulatory surgery.

Remifentanil is also useful during ambulatory surgery, because of its rapid onset and short duration of action, which leads to rapid awakening and recovery from anesthesia [41]. Because of the rapid analgesic offset of remifentanil, it may be necessary to also use long-acting opioids or non-opioid analgesics to provide postoperative pain relief. The possibility that remifentanil can induce acute tolerance and hyperalgesia after several hours of infusion or repeated administration is still controversial [42]. Lenz et al. [43] reported that intraoperative remifentanil at high doses $(0.3-0.5 \mu \mathrm{g} / \mathrm{kg} / \mathrm{min})$ increased postoperative pain and morphine consumption. Another study reported that remifentanil did not increase the frequency of PONV or the use of analgesics after ambulatory surgery [44].

The recently introduced agent sugammadex binds directly to steroidal non-depolarizing muscle relaxants, such as lipidsoluble rocuronium and vecuronium, deactivating the drugs and reversing the effects of muscle relaxation [45]. The effect of sugammadex is faster and stronger than that of anticholinesterase, which indirectly reverses muscle relaxation through increasing acetylcholine concentrations. Additionally, as there are no side effects associated with parasympathetic nerve disorders due to increased acetylcholine concentrations, concomitant use of anticholinergic drugs is unnecessary [46]. Sugammadex is suitable for use in ambulatory anesthesia because of its ability to reverse rocuronium-induced neuromuscular blockade at any stage and improve patient safety [47].

\section{Regional anesthesia}

The major types of regional anesthesia include peripheral nerve blockade (with or without a continuous peripheral nerve catheter) and neuraxial blockade [48]. Regional anesthesia can avoid the side effects often caused by general anesthesia, such as nausea, vomiting, dizziness, residual muscle relaxation, and aspiration pneumonia. Additionally, analgesic effects can onset from the early postoperative period [48]. However, regional anesthesia requires more time to take effect, and in cases in which the anesthesia is unsuccessful or incomplete, general anesthesia is used. An anesthesia induction room, in which a nerve block can be activated before surgery, can be of great help in operations $[49,50]$. Furthermore, the postoperative analgesic effect is greater with supplementation by peripheral nerve block in patients undergoing general anesthesia than with the use of local anesthesia. Thus, the use of narcotic analgesics, and their consequent side effects, can be reduced, leading to a more rapid recovery [51]. However, when using central axonal block, appropriate local anesthetics and anesthetic supplements should be selected and administered at appropriate dosages to prevent delays in the discharge of ambulatory surgery patients [52].

\section{Monitored anesthesia care}

MAC is a method in which patients are anesthetized by intravenous injection of analgesic and sedative drugs. Rather than being used alone, MAC is often used in conjunction with local infiltration anesthesia and peripheral nerve block. MAC can increase patient satisfaction and shorten recovery times compared with general anesthesia or neuraxial block $[53,54]$. Recently, propofol, low-dose ketamine, and dexmedetomidine have been used increasingly because they can reduce the incidence of respiratory depression caused by sedative-analgesic use [55-57]. Because respiratory depression is caused by excessive sedation, special attention must be paid to this possibility by the staff performing ambulatory surgery.

\section{Controversies in anesthetic methods}

\section{Total intravenous anesthesia (TIVA) versus inhalation anesthesia}

The advantages of TIVA versus inhalation anesthesia have been discussed previously [58]. TIVA in ambulatory surgery is advantageous due to rapid recovery, without agitation or behavioral disturbances, and a low incidence of PONV. It also helps to avoid environmental pollution, and excludes the possibility of malignant hyperthermia. However, the literature provides no compelling evidence for the advantages of one method or the other in improving the recovery profile and cognitive function $[59,60]$.

\section{General anesthesia versus regional anesthesia}

Large-scale studies have shown that regional anesthesia has a lower morbidity rate than general anesthesia [61-64]. However, these large-scale studies have several drawbacks and the results 
are often difficult to generalize to other clinical settings. The drawbacks are as follows [65]. First, little or no information is included on the type of general anesthesia, or pain management regime, or on the details of the regional anesthesia technique used. Second, a potential selection bias can occur because the comparison is not random. Third, no accurate data is provided on treatment principles or pain control. These studies provide no clear guidelines for selection of the optimal anesthesia method (general or regional).

\section{Postoperative Anesthetic Management}

For successful ambulatory surgery, postoperative pain, nausea, vomiting, dizziness, and intestinal and bladder obstruction, which may delay a patient's discharge and increase the likelihood of re admission, must be minimized. Pain and PONV, the most common complications after ambulatory anesthesia and surgery, are closely related. Excessive use of opioids to control postoperative pain may cause PONV and pain itself is a risk factor for PONV. Thus, perioperative treatment to mitigate against such complications is essential. The rate of unexpected hospitalization, which represents an important indicator of ambulatory surgery quality, is usually reported as $1-2 \%$ [66]. The most common causes of such hospitalizations are pain, hemorrhage, and the need to perform more extensive surgery than initially planned $[67,68]$.

\section{Postoperative pain management}

Postoperative pain management, which is an integral facet of successful ambulatory anesthesia, includes regional nerve block and analgesic administration. The infiltration of local anesthetics or nerve block at the surgical site at the conclusion of the operation may reduce the dose of anesthetics and analgesics required thereafter [69]. Thus, the recovery time is shortened, and anxiety or excitement in the recovery room due to pain can be alleviated. Pain control following a successful surgical operation increases the patient's speed of recovery and return to activities of daily living [70]. The use of non-steroidal anti-inflammatory drugs (NSAIDs) alone is relatively ineffective in controlling severe pain, while the use of narcotic analgesics alone may cause various postoperative side effects, such as nausea, vomiting, dizziness, and constipation. Multimodal or balanced analgesia therapy, or the use of more than one pain relief method, can increase analgesic effects while simultaneously reducing the side effects associated with certain medications [71]. Thus, this multimodal approach has become standard in pain control therapy for ambulatory surgical operations [72]. Recently, larger-scale procedures associated with severe postoperative pain, such as laparoscopic nephrectomy, prostatectomy, shoulder and knee reconstruction, and hysterectomy, are increasingly being performed on an ambulatory basis or with short hospitalization periods [73]. The perioperative use of multimodal analgesia therapies with both narcotic and non-narcotic analgesics can increase the speed of a patient's quick recovery and improve satisfaction rates.

Narcotic analgesics continue to play a prominent role in relieving postoperative acute pain. However, as the frequency of reports of minimally invasive surgery with relatively low postoperative pain increases steadily, so too does the role of nonnarcotic analgesics as prophylactic agents [73]. Furthermore, NSAIDs, acetaminophen, ketamine, alpha-2 agonists, and gabapentin have been used increasingly in multimodal analgesia therapies for postoperative pain control [74]. Ideally, a combination of these non-narcotic analgesics would be used to ensure excellent pain relief and ultimately eliminate the use of narcotic analgesics. Multimodal analgesia therapy minimizes postoperative pain, reduces organ damage resulting from the use of narcotic analgesics, and facilitates recovery from anesthesia; thus, it has become an important element of ambulatory surgery.

\section{Postoperative nausea and vomiting}

While the frequency of nausea and vomiting varies, approximately $30-50 \%$ of patients report such symptoms [75,76]. Even if other problems associated with surgery and anesthesia are alleviated, in cases of severe nausea or vomiting, patient discharge may still be delayed and unexpected hospitalization may be necessary. Despite the development of various new anti-emetics, the incidence of nausea and vomiting due to patient, surgery, and anesthesia-related risk factors remains high, at around 30\% [77]. Major risk factors for PONV include female gender, nonsmoking status, a history of nausea and vomiting after motion sickness or surgery, and previous use of inhalation anesthesia or narcotic analgesics [78]. For adults with more than two of these risk factors, the administration of multimodal anti-emetics, such as droperidol, dexamethasone, and ondansetron, is recommended [79]. Treatment of PONV requires the administration of antiemetic drugs of a different pharmacological class than the initial prophylactic drugs, and low-dose 5-hydroxytryptamine receptor antagonists are recommended unless prophylaxis is indicated [80]. Furthermore, to reduce the risk of nausea and vomiting, adequate use of propofol, fluid therapy, and minimization of narcotic analgesics during perioperative treatment are also effective [81].

\section{Recovery}

The process of recovery from anesthesia can be divided into three stages: early, middle, and late $[3,66]$. Early recovery refers 
to the period between awakening from anesthesia and restoration of protective reflexes and motor capacity. Up to this point, the patient remains in the PACU, where vital signs and oxygen saturation are monitored. If necessary, oxygen, analgesics, and anti-emetics can be administered. Most hospitals that conduct ambulatory surgery have step-down units or ambulatory surgical units that assist patients in the middle stages with preparation for discharge. Patients in the middle recovery phase stay in step-down units and are nursed in resting chairs. They are considered ready for discharge when they are capable of walking, drinking, and urinating. Transfer decisions from the PACU to the step-down unit commonly follow evaluations done using the modified Aldrete scoring system [82] or White's fast-track criteria [83]. Limitations of the modified Aldrete score include that it does not address pain, nausea, or vomiting, which are common side effects of a PACU stay [82]. The modified Aldrete score is also not ideal for determining fast-tracking bypass in ambulatory settings or patients undergoing regional anesthesia [48]. When a simple operation is performed using short-acting anesthetics, such as propofol, sevoflurane, or desflurane, there are many cases in which the patient recovers consciousness, regular breathing, and stable vital signs in the operating room. The use of a cerebral monitoring device, such as the bispectral index, may be advantageous, with the early aim being to help titration toward a lower anesthetic dose [84,85]. In such cases of early recovery, a fast-tracking method that involves directly moving the patient to the step-down unit without passing through the PACU can be applied to reduce medical expenses. White's fasttrack criteria are used to evaluate the decision to admit a patient into a step-down unit without going through the PACU [83]. The more recently introduced 'WAKE' score includes not only the modified Aldrete score (maximum score = 10), but also "zero tolerance" criteria to assess post-operative pain, PONV, tremors, itching, and orthostatic symptoms (dizziness, hypotension) [86]. The WAKE score appears more suitable for the evaluation and rapid follow-up of outpatients who have undergone regional anesthesia, general anesthesia, or MAC [48]. The late recovery period refers to the period prior to a patient being able to return to work and daily life, after all functions have recovered fully post discharge. For a safe discharge, the patient must have stable vital signs and show restoration of full orientation. Furthermore, the patient must be able to walk without dizziness and have little to no pain, nausea, vomiting, or surgical-site bleeding. When the patient has completed the second recovery phase, the Post Anesthesia Discharge Scoring System may be used to decide whether or not they can be discharged from the hospital [87]. In US and Canadian hospitals, to return home, all outpatients who receive sedative or analgesic medications must have be escorted by a responsible adult [66]. A responsible adult escort must be provided with printed instructions, including detailed informa- tion regarding precautions, guidelines, and the medical personnel to contact in case of an emergency [14]. During this process, close communication between patients and medical staff, as well as postoperative follow-up appointments, should be ensured.

\section{Pre-discharge controversies}

Mandatory oral intake may not be warranted because it can cause nausea and vomiting and may unnecessarily delay discharge $[14,66]$. Patients at low risk, such as those who have no urinary retention and have not undergone hernia or urology surgery, can be discharged home without urination. They should be instructed to return to the hospital if they cannot void within 6-8 h after returning home [66]. However, it should be a requirement for patients at high risk of urinary retention (such as those undergoing anorectal surgeries and lower limb joint arthroplasty, and those with benign prostatic hyperplasia) to void prior to discharge and display a residual volume $<300 \mathrm{ml}$, as measured by ultrasound of the bladder [66].

\section{Conclusions}

Developments in medical technology have resulted in a rapid increase in the use of ambulatory surgery. The use of fast- and short-acting anesthetics, analgesics, and muscle relaxants, as well as improved brain monitoring techniques, have reduced anesthetic complications during recovery. Additionally, improvements in surgical techniques have allowed surgeons to perform more invasive surgical procedures and complex medical procedures on an ambulatory basis. When deciding on ambulatory surgery, it is important to select the type of surgery only after evaluating the patient's overall condition, including any past history and family history. The choice of anesthesia technique according to the patient's condition and type of surgery is an important factor affecting recovery and discharge. Postoperative complications, such as pain, nausea, and vomiting are common; they can delay recovery and the possibility of readmission is high if they are present. Thus, a multimodal and prophylactic approach to prevent postoperative complications should be planned to enable early discharge and return to daily life. To optimize the patient's status, active cooperation among the patient, the patient's family, nurses, surgeons, and medical staff, including anesthesiologists, is required. 


\section{References}

1. Shnaider I, Chung F. Outcomes in day surgery. Curr Opin Anaesthesiol 2006; 19: 622-9.

2. American Society of Anesthesiologists Task Force on Postanesthetic Care. Practice guidelines for postanesthetic care: a report by the American Society of Anesthesiologists Task Force on Postanesthetic Care. Anesthesiology 2002; 96: 742-52.

3. McGrath B, Chung F. Postoperative recovery and discharge. Anesthesiol Clin North America 2003; 21: 367-86.

4. White PF, Eng M. Fast-track anesthetic techniques for ambulatory surgery. Curr Opin Anaesthesiol 2007; 20: 545-57.

5. Kehlet H, Wilmore DW. Multimodal strategies to improve surgical outcome. Am J Surg 2002; 183: 630-41.

6. Smith I, Cooke T, Jackson I, Fitzpatrick R. Rising to the challenges of achieving day surgery targets. Anaesthesia 2006; 61: 1191-9.

7. De Lathouwer C, Poullier JP. How much ambulatory surgery in the World in 1996-1997 and trends? Ambul Surg 2000; 8: $191-210$.

8. Cullen KA, Hall MJ, Golosinskiy A. Ambulatory surgery in the United States, 2006. Natl Health Stat Rep 2009; (11): 1-25. Available from https:/www.researchgate.net/profile/Karen_Cullen3/publication/24209006_Ambulatory_Surgery_in_the_United_States_2006/ links/0046353b42978e1768000000/Ambulatory-Surgery-in-the-United-States-2006.pdf

9. Pollard JB, Zboray AL, Mazze RI. Economic benefits attributed to opening a preoperative evaluation clinic for outpatients. Anesth Analg 1996; 83: 407-10.

10. Hand R, Levin P, Stanziola A. The causes of cancelled elective surgery. Qual Assur Util Rev 1990; 5: 2-6.

11. Conway JB, Goldberg J, Chung F. Preadmission anaesthesia consultation clinic. Can J Anaesth 1992; 39: 1051-7.

12. MacDonald JB, Dutton MJ, Stott DJ, Hamblen DL. Evaluation of pre-admission screening of elderly patients accepted for major joint replacement. Health Bull (Edinb) 1992; 50: 54-60.

13. Boothe P, Finegan BA. Changing the admission process for elective surgery: an economic analysis. Can J Anaesth 1995; 42: 391-4.

14. Association of Anaesthetists of Great Britain and Ireland; British Association of Day Surgery. Day case and short stay surgery: 2. Anaesthesia 2011; 66: 417-34.

15. Ansell GL, Montgomery JE. Outcome of ASA III patients undergoing day case surgery. Br J Anaesth 2004; 92: 71-4.

16. Aldwinckle RJ, Montgomery JE. Unplanned admission rates and postdischarge complications in patients over the age of 70 following day case surgery. Anaesthesia 2004; 59: 57-9.

17. Canet J, Raeder J, Rasmussen LS, Enlund M, Kuipers HM, Hanning CD, et al. Cognitive dysfunction after minor surgery in the elderly. Acta Anaesthesiol Scand 2003; 47: 1204-10.

18. Davies KE, Houghton K, Montgomery JE. Obesity and day-case surgery. Anaesthesia 2001; 56: 1112-5.

19. Moon TS, Joshi GP. Are morbidly obese patients suitable for ambulatory surgery? Curr Opin Anaesthesiol 2016; 29: 141-5.

20. McLaren RG, Moffitt EA. Case history number 92: Prolonged apnea after succinylcholine in a dental outpatient. Anesth Analg 1976; 55: 737-9.

21. Carr AS, Lerman J, Cunliffe M, McLeod ME, Britt BA. Incidence of malignant hyperthermia reactions in 2,214 patients undergoing muscle biopsy. Can J Anaesth 1995; 42: 281-6.

22. Hackl W, Mauritz W, Winkler M, Sporn P, Steinbereithner K. Anaesthesia in malignant hyperthermia-susceptible patients without dantrolene prophylaxis: a report of 30 cases. Acta Anaesthesiol Scand 1990; 34: 534-7.

23. Bryson GL, Chung F, Cox RG, Crowe MJ, Fuller J, Henderson C, et al. Patient selection in ambulatory anesthesia - an evidence-based review: part II. Can J Anaesth 2004; 51: 782-94.

24. Apfel CC, Läärä E, Koivuranta M, Greim CA, Roewer N. A simplified risk score for predicting postoperative nausea and vomiting: conclusions from cross-validations between two centers. Anesthesiology 1999; 91: 693-700.

25. Hinkelbein J, Hohn A, Genzwürker H. Airway management for anaesthesia in the ambulatory setting. Curr Opin Anaesthesiol 2015; 28: 642-7.

26. Smith I, Jackson I. Beta-blockers, calcium channel blockers, angiotensin converting enzyme inhibitors and angiotensin receptor blockers: should they be stopped or not before ambulatory anaesthesia? Curr Opin Anaesthesiol 2010; 23: 687-90.

27. Bryson GL, Chung F, Finegan BA, Friedman Z, Miller DR, van Vlymen J, et al. Patient selection in ambulatory anesthesia - an evidencebased review: part I. Can J Anaesth 2004; 51: 768-81.

28. Chan MT, Wang CY, Seet E, Tam S, Lai HY, Walker S, et al. Postoperative vascular complications in unrecognised Obstructive Sleep apnoea (POSA) study protocol: an observational cohort study in moderate-to-high risk patients undergoing non-cardiac surgery. BMJ Open 2014; 4: e004097.

29. Joshi GP, Ankichetty SP, Gan TJ, Chung F. Society for Ambulatory Anesthesia consensus statement on preoperative selection of adult patients with obstructive sleep apnea scheduled for ambulatory surgery. Anesth Analg 2012; 115: 1060-8.

30. Chung F, Yegneswaran B, Liao P, Chung SA, Vairavanathan S, Islam S, et al. STOP questionnaire: a tool to screen patients for obstructive sleep apnea. Anesthesiology 2008; 108: 812-21.

31. Smith I, White PF, Nathanson M, Gouldson R. Propofol. An update on its clinical use. Anesthesiology 1994; 81: 1005-43.

32. Patel SS, Goa KL. Desflurane. A review of its pharmacodynamic and pharmacokinetic properties and its efficacy in general anaesthesia. Drugs 1995; 50: 742-67.

33. Smith I, Nathanson MH, White PF. The role of sevoflurane in outpatient anesthesia. Anesth Analg 1995; 81(6 Suppl): S67-72. 
34. Apfelbaum JL, Walawander CA, Grasela TH, Wise P, McLeskey C, Roizen MF, et al. Eliminating intensive postoperative care in same-day surgery patients using short-acting anesthetics. Anesthesiology 2002; 97: 66-74.

35. Apfel CC, Kranke P, Katz MH, Goepfert C, Papenfuss T, Rauch S, et al. Volatile anaesthetics may be the main cause of early but not delayed postoperative vomiting: a randomized controlled trial of factorial design. Br J Anaesth 2002; 88: 659-68.

36. Gan TJ, Meyer TA, Apfel CC, Chung F, Davis PJ, Habib AS, et al. Society for Ambulatory Anesthesia guidelines for the management of postoperative nausea and vomiting. Anesth Analg 2007; 105: 1615-28.

37. Jakobsson J. Desflurane: a clinical update of a third-generation inhaled anaesthetic. Acta Anaesthesiol Scand 2012; 56: 420-32.

38. Dexter F, Bayman EO, Epstein RH. Statistical modeling of average and variability of time to extubation for meta-analysis comparing desflurane to sevoflurane. Anesth Analg 2010; 110: 570-80.

39. White PF, Tang J, Wender RH, Yumul R, Stokes OJ, Sloninsky A, et al. Desflurane versus sevoflurane for maintenance of outpatient anesthesia: the effect on early versus late recovery and perioperative coughing. Anesth Analg 2009; 109: 387-93.

40. Pavlin DJ, Rapp SE, Polissar NL, Malmgren JA, Koerschgen M, Keyes H. Factors affecting discharge time in adult outpatients. Anesth Analg 1998; 87: 816-26.

41. Minto CF, Schnider TW, Shafer SL. Pharmacokinetics and pharmacodynamics of remifentanil. II. Model application. Anesthesiology 1997; 86: 24-33.

42. Guignard B, Bossard AE, Coste C, Sessler DI, Lebrault C, Alfonsi P, et al. Acute opioid tolerance: intraoperative remifentanil increases postoperative pain and morphine requirement. Anesthesiology 2000; 93: 409-17.

43. Lenz H, Raeder J, Hoymork SC. Administration of fentanyl before remifentanil-based anaesthesia has no influence on post-operative pain or analgesic consumption. Acta Anaesthesiol Scand 2008; 52: 149-54.

44. Hara R, Hirota K, Sato M, Tanabe H, Yazawa T, Habara T, et al. The impact of remifentanil on incidence and severity of postoperative nausea and vomiting in a university hospital-based ambulatory surgery center: a retrospective observation study. Korean J Anesthesiol 2013; 65: $142-6$

45. Hunter JM, Flockton EA. The doughnut and the hole: a new pharmacological concept for anaesthetists. Br J Anaesth 2006; 97: 123-6.

46. Sacan O, White PF, Tufanogullari B, Klein K. Sugammadex reversal of rocuronium-induced neuromuscular blockade: a comparison with neostigmine-glycopyrrolate and edrophonium-atropine. Anesth Analg 2007; 104: 569-74.

47. Schreiber JU. Management of neuromuscular blockade in ambulatory patients. Curr Opin Anaesthesiol 2014; 27: 583-8.

48. Moore JG, Ross SM, Williams BA. Regional anesthesia and ambulatory surgery. Curr Opin Anaesthesiol 2013; 26: 652-60.

49. Caggiano NM, Avery DM 3rd, Matullo KS. The effect of anesthesia type on nonsurgical operating room time. J Hand Surg Am 2015; 40: 1202-9.e1.

50. Head SJ, Seib R, Osborn JA, Schwarz SK. A "swing room" model based on regional anesthesia reduces turnover time and increases case throughput. Can J Anaesth 2011; 58: 725-32.

51. Hadzic A, Arliss J, Kerimoglu B, Karaca PE, Yufa M, Claudio RE, et al. A comparison of infraclavicular nerve block versus general anesthesia for hand and wrist day-case surgeries. Anesthesiology 2004; 101: 127-32.

52. Kehlet H, White PF. Optimizing anesthesia for inguinal herniorrhaphy: general, regional, or local anesthesia? Anesth Analg 2001; 93: 13679.

53. Sá Rêgo MM, Watcha MF, White PF. The changing role of monitored anesthesia care in the ambulatory setting. Anesth Analg 1997; 85: 1020-36.

54. Bang YS, Park C, Lee SY, Kim M, Lee J, Lee T. Comparison between monitored anesthesia care with remifentanil under ilioinguinal hypogastric nerve block and spinal anesthesia for herniorrhaphy. Korean J Anesthesiol 2013; 64: 414-9.

55. Badrinath S, Avramov MN, Shadrick M, Witt TR, Ivankovich AD. The use of a ketamine-propofol combination during monitored anesthesia care. Anesth Analg 2000; 90: 858-62.

56. Tan T, Bhinder R, Carey M, Briggs L. Day-surgery patients anesthetized with propofol have less postoperative pain than those anesthetized with sevoflurane. Anesth Analg 2010; 111: 83-5.

57. Arain SR, Ebert TJ. The efficacy, side effects, and recovery characteristics of dexmedetomidine versus propofol when used for intraoperative sedation. Anesth Analg 2002; 95: 461-6.

58. Joshi GP. Inhalational techniques in ambulatory anesthesia. Anesthesiol Clin North America 2003; 21: 263-72.

59. Lindqvist M, Schening A, Granstrom A, Bjorne H, Jakobsson JG. Cognitive recovery after ambulatory anaesthesia based on desflurane or propofol: a prospective randomised study. Acta Anaesthesiol Scand 2014; 58: 1111-20.

60. Ortiz AC, Atallah AN, Matos D, da Silva EM. Intravenous versus inhalational anaesthesia for paediatric outpatient surgery. Cochrane Database Syst Rev 2014; (2): CD009015.

61. Basques BA, Toy JO, Bohl DD, Golinvaux NS, Grauer JN. General compared with spinal anesthesia for total hip arthroplasty. J Bone Joint Surg Am 2015; 97: 455-61.

62. Opperer M, Danninger T, Stundner O, Memtsoudis SG. Perioperative outcomes and type of anesthesia in hip surgical patients: An evidence based review. World J Orthop 2014; 5: 336-43.

63. Memtsoudis SG, Sun X, Chiu YL, Stundner O, Liu SS, Banerjee S, et al. Perioperative comparative effectiveness of anesthetic technique in orthopedic patients. Anesthesiology 2013; 118: 1046-58. 
64. Memtsoudis SG, Rasul R, Suzuki S, Poeran J, Danninger T, Wu C, et al. Does the impact of the type of anesthesia on outcomes differ by patient age and comorbidity burden? Reg Anesth Pain Med 2014; 39: 112-9.

65. Kehlet H, Aasvang EK. Regional or general anesthesia for fast-track hip and knee replacement - what is the evidence? F1000Res $2015 ; 4$.

66. Awad IT, Chung F. Factors affecting recovery and discharge following ambulatory surgery. Can J Anaesth 2006; 53: 858-72.

67. Osborne GA, Rudkin GE. Outcome after day-care surgery in a major teaching hospital. Anaesth Intensive Care 1993; $21: 822-7$.

68. Fortier J, Chung F, Su J. Unanticipated admission after ambulatory surgery--a prospective study. Can J Anaesth 1998; 45: 612-9.

69. Schug SA, Chong C. Pain management after ambulatory surgery. Curr Opin Anaesthesiol 2009; 22: 738-43.

70. Mattila K, Toivonen J, Janhunen L, Rosenberg PH, Hynynen M. Postdischarge symptoms after ambulatory surgery: first-week incidence, intensity, and risk factors. Anesth Analg 2005; 101: 1643-50.

71. Kehlet H, Dahl JB. The value of "multimodal" or "balanced analgesia" in postoperative pain treatment. Anesth Analg 1993; 77: $1048-56$.

72. Kehlet H. Postoperative opioid sparing to hasten recovery: what are the issues? Anesthesiology 2005; 102: 1083-5.

73. White PF. Ambulatory anesthesia advances into the new millennium. Anesth Analg 2000; 90: 1234-5.

74. White PF. The changing role of non-opioid analgesic techniques in the management of postoperative pain. Anesth Analg 2005; 101(5 Suppl): S5-22.

75. Gan TJ. Postoperative nausea and vomiting--can it be eliminated? JAMA 2002; 287: 1233-6.

76. Golembiewski J, Chernin E, Chopra T. Prevention and treatment of postoperative nausea and vomiting. Am J Health Syst Pharm 2005; 62: 1247-60.

77. Watcha MF, White PF. Postoperative nausea and vomiting. Its etiology, treatment, and prevention. Anesthesiology 1992; $77:$ 162-84.

78. Apfel CC, Roewer N. Risk assessment of postoperative nausea and vomiting. Int Anesthesiol Clin 2003; 41: 13-32.

79. White PF, Watcha MF. Postoperative nausea and vomiting: prophylaxis versus treatment. Anesth Analg 1999; 89: 1337-9.

80. Gan TJ, Diemunsch P, Habib AS, Kovac A, Kranke P, Meyer TA, et al. Consensus guidelines for the management of postoperative nausea and vomiting. Anesth Analg 2014; 118: 85-113.

81. Scuderi PE, James RL, Harris L, Mims GR 3rd. Multimodal antiemetic management prevents early postoperative vomiting after outpatient laparoscopy. Anesth Analg 2000; 91: 1408-14.

82. Aldrete JA. The post-anesthesia recovery score revisited. J Clin Anesth 1995; 7: 89-91.

83. White PF, Song D. New criteria for fast-tracking after outpatient anesthesia: a comparison with the modified Aldrete's scoring system. Anesth Analg 1999; 88: 1069-72.

84. Avidan MS, Zhang L, Burnside BA, Finkel KJ, Searleman AC, Selvidge JA, et al. Anesthesia awareness and the bispectral index. N Engl J Med 2008; 358: 1097-108.

85. White PF, Ma H, Tang J, Wender RH, Sloninsky A, Kariger R. Does the use of electroencephalographic bispectral index or auditory evoked potential index monitoring facilitate recovery after desflurane anesthesia in the ambulatory setting? Anesthesiology 2004; 100: 811-7.

86. Williams BA, Kentor ML. The WAKE@ score: patient-centered ambulatory anesthesia and fast-tracking outcomes criteria. Int Anesthesiol Clin 2011; 49: 33-43.

87. Chung F, Chan VW, Ong D. A post-anesthetic discharge scoring system for home readiness after ambulatory surgery. J Clin Anesth 1995; 7: 500-6. 